Published in final edited form as:

Arch Neurol. 2009 April ; 66(4): 433-434. doi:10.1001/archneurol.2009.29.

\title{
Brain Traffic:
}

\section{Subcellular Transport of the Amyloid Precursor Protein}

\section{Richard Mayeux, MD, MSc and Peter St. George-Hyslop, MD}

\begin{abstract}
The progression from proteolysis of the amyloid precursor protein (APP) to the formation of aggregated amyloid- $\beta$ peptide (A $\beta$ ) deposits forms the basis of the amyloid hypothesis for the pathogenesis of Alzheimer disease. ${ }^{1}$ Key steps in APP processing occur in subcellular compartments. Amyloid- $\beta$ is one of several end products that originate from the sequential proteolysis by $\beta$-secretase and $\gamma$-secretase cleavage of the transmembrane APP. While A $\beta$ can range in size from 37 to 43 amino acids, it is the $A \beta_{42}$ peptide that appears to be the foundation of fibrillar plaque formation in the brains of patients with Alzheimer disease. Alterations in the intracellular transport of APP can directly influence whether APP undergoes $\alpha$-secretase enzymatic activity, releasing a nontoxic peptide, $\alpha$-secretase-cleaved soluble APP (sAPP $\alpha$ ), or follows $\beta$-secretase and $\gamma$-secretase enzymatic pathways, leading to generation of the neurotoxic forms of $A \beta$. While the $\alpha$-secretase enzymes are found at the cell surface, $\beta$-secretase lies within the Golgi apparatus and endosomes, the $\gamma$-secretase complex in the endoplasmic reticulum, lysosomes, and the cell surface. When APP is moved into the endosome, it is cleaved by $\beta$-secretase and then transported either to the cell surface or to the lysosome to be further processed by $\gamma$-secretase to form A $\beta$. However, when APP accumulates at the cell surface, it has a greater chance of interacting with $\alpha$-secretase to form nonamyloid-forming sAPP $\alpha$.
\end{abstract}

SORL1 (also known as LR11 and SorLA) is 1 of several members of the low-density lipoprotein receptor family that interact and influence the cellular localization and processing of APP. SORL1 is a highly conserved type 1 receptor with vacuolar protein sorting and lowdensity lipoprotein-receptor class A and fibronectin domains. The low-density lipoproteinreceptor domain also serves as a binding site for apolipoprotein E. A single transmembrane domain carries a motif that specifically mediates SORL1 interaction with proteins involved in Golgi apparatus and endosome sorting of proteins, such as APP. An inherent modification in SORL1 enables it to control the clearance of some glycoproteins, modulate interactions with other proteins, and influence intracellular trafficking. ${ }^{1}$ SORL1 and APP are colocalized within the perinuclear region of neurons and, when coexpressed in vitro, result in a complex formation in which there is SORL1-dependent translocation of APP.2 The active receptors for SORL1 are in the Golgi network as well as the endosome, further supporting an influential role in intracellular trafficking of APP. It has been suggested that SORL1 acts as a regulatory gate keeper for the amyloidogenic and nonamyloidogenic pathways, determining the ultimate destination for APP.2,3 When SORL1 effectively binds with APP, there is a reduction in SAPP $\beta$ and $A \beta$, but when deficient, as in SORL1-knockout mice, the result is high levels of sAPP $\beta$ and $A \beta .^{2}$ In a cell culture, Anderson et $\mathrm{al}^{2}$ demonstrated that by increasing SORL1

(C2009 American Medical Association. All rights reserved.

Correspondence: Dr Mayeux, Gertrude H. Sergievsky Center, Columbia University, 630 West 168th St, New York, NY 10032 (rpm2@columbia.edu).

Author Contributions: Study concept and design: Mayeux and St. George-Hyslop. Analysis and interpretation of data: St. GeorgeHyslop. Drafting of the manuscript: Mayeux and St. George-Hyslop. Critical revision of the manuscript for important intellectual content: Mayeux and St. George-Hyslop. Obtained funding: Mayeux.

Financial Disclosure: None reported. 
levels in neurons, APP was sequestered in intracellular compartments, reducing further processing of $A \beta$. This indicated to them that, in the converse situation, a decrease in SORL1 expression might be responsible for the increased $\mathrm{A} \beta$ production in patients with Alzheimer disease. The neuronal-sorting receptor SORL1 interacts with APP, in vivo and in vitro, which in turn affects the trafficking of this protein through the cell and proteolytic processing in the brain.

In patients with Alzheimer disease as well as those with the amnesic form of mild cognitive impairment, an early stage of Alzheimer disease, the expression of SORL1 is reduced in the brain. ${ }^{4,5}$ Ablation of SORL1 expression in mice resulted in increased $\mathrm{A} \beta$ in the brain, supporting the view that SORL1 is involved in disease pathogenesis that contributes to plaque formation. ${ }^{2}$ Whether this decrease in expression is causal or reactive has been clarified somewhat by the discovery of inherited variants in SORL1 that are associated with Alzheimer disease. Rogaeva et $\mathrm{al}^{3}$ reported that 2 clusters of variant single-nucleotide polymorphisms at the $3^{\prime}$ and $5^{\prime}$ ends of the gene encoding SORL1 on chromosome 11q23.2 were associated with familial and sporadic forms of Alzheimer disease. These results have subsequently been tested in several independent, nonoverlapping data sets composed of patients with Alzheimer disease and controls. Although not all studies support the association between Alzheimer disease and variants in SORL1, several independent reports have observed significant associations clustering in the same 2 regions of SORL1 but not always the same single-nucleotide polymorphisms. ${ }^{6-8}$ The presence of genetic variants across multiple domains of SORL1 suggests allelic heterogeneity, and the absence of these variants in some data sets might be the result of locus heterogeneity, which is not unusual in either monogenic or complex disorders, such as Alzheimer disease.

SORL1 variants have also been associated with a cerebrospinal fluid endophenotype of Alzheimer disease. Specifically, a 3-marker SORL1 haplotype was associated with reduced cerebrospinal fluid $\mathrm{A} \beta_{42}$ concentrations in patients with Alzheimer disease. ${ }^{9}$ The study by Ma and colleagues ${ }^{10}$ in this issue of Archives extends this observation in a clinically meaningful way by first showing a strong correlation between cerebrospinal fluid SORL1, termed LR11 in their article, and $A \beta_{42}$ concentrations. Cerebrospinal fluid levels of $A \beta_{42}$ are typically reduced in patients with Alzheimer disease. When $\mathrm{A} \beta_{42}$ was combined with cerebrospinal fluid levels of SORL1, there was a statistically significant increase in the sensitivity and specificity. The main effect of the measurement of cerebrospinal fluid SORL1 was reduction in the falsepositive rate when added to $A \beta_{42}$ concentrations as noted in Figure $5 \mathrm{~A}$ of the article. Not cerebrospinal fluid measurements of phosphorylated tau, total tau, or apolipoprotein $\mathrm{E}$ contributed to the diagnostic accuracy, though the sample size was small. Taken together, these observations support the hypothesis that SORL1 is directly involved in the pathogenesis of Alzheimer disease. More importantly, it is clear that a better understanding of subcellular trafficking of APP as well as the various functional roles of SORL1 may point to a novel therapeutic strategy that has not yet been considered.

\section{Acknowledgments}

Funding/Support: This work was supported by grants R37-AG15473 and P01-AG07232 from the National Institute on Aging, National Institutes of Health; the Alzheimer Association; Blanchett Hooker Rockefeller Foundation; and Charles S. Robertson Gift (Dr Mayeux); and The Wellcome Trust; Howard Hughes Medical Institute; Canadian Institutes of Health Research; Ontario Research Fund; and the Alzheimer Association of Ontario (Dr St. GeorgeHyslop).

\section{REFERENCES}

1. Cam JA, Bu G. Modulation of beta-amyloid precursor protein trafficking and processing by the low density lipoprotein receptor family. Mol Neurodegener 2006;1:8. [PubMed: 16930455] 
2. Andersen OM, Reiche J, Schmidt V, et al. Neuronal sorting protein-related receptor sorLA/LR11 regulates processing of the amyloid precursor protein. Proc Natl Acad Sci U S A 2005;102(38):1346113466. [PubMed: 16174740]

3. Rogaeva E, Meng Y, Lee JH, et al. The neuronal sortilin-related receptor SORL1 is genetically associated with Alzheimer disease. Nat Genet 2007;39(2):168-177. [PubMed: 17220890]

4. Dodson SE, Gearing M, Lippa CF, Montine TJ, Levey AI, Lah JJ. LR11/SorLA expression is reduced in sporadic Alzheimer disease but not in familial Alzheimer disease. J Neuropathol Exp Neurol 2006;65(9):866-872. [PubMed: 16957580]

5. Sager KL, Wuu J, Leurgans SE, et al. Neuronal LR11/sorLA expression is reduced in mild cognitive impairment. Ann Neurol 2007;62(6):640-647. [PubMed: 17721864]

6. Lee JH, Cheng R, Honig LS, Vonsattel JP, Clark L, Mayeux R. Association between genetic variants in SORL1 and autopsy-confirmed Alzheimer disease. Neurology 2008;70(11):887-889. [PubMed: 17978276]

7. Bettens K, Brouwers N, Engelborghs S, De Deyn PP, Van Broeckhoven C, Sleegers K. SORL1 is genetically associated with increased risk for late-onset Alzheimer disease in the Belgian population. Hum Mutat 2008;29(5):769-770. [PubMed: 18407551]

8. Meng Y, Lee JH, Cheng R, St George-Hyslop P, Mayeux R, Farrer LA. Association between SORL1 and Alzheimer's disease in a genome-wide study. Neuroreport 2007;18(17):1761-1764. [PubMed: 18090307]

9. Kölsch H, Jessen F, Wiltfang JM, et al. Influence of SORL1 gene variants: association with CSF amyloid-beta products in probable Alzheimer's disease. Neurosci Lett 2008;440(1):68-71. [PubMed: 18541377]

10. Ma Q-L, Galasko DR, Ringman JM, et al. Reduction of SorLA/LR11, a sorting protein limiting $\beta$ amyloid production, in Alzheimer disease cerebrospinal fluid. Arch Neurol 2009;66(4):448-457.

[PubMed: 19364929] 